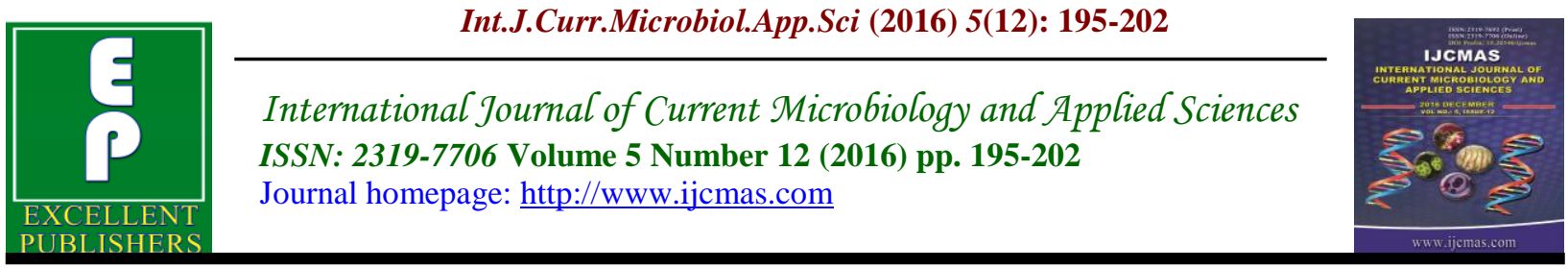

Original Research Article

http://dx.doi.org/10.20546/ijcmas.2016.512.021

\title{
Role of Serology in Diagnosis of Human Hydatidosis: Experience from a Tertiary Care Hospital
}

\author{
Mridula Madiyal $^{1 *}$, Barnini Banerjee ${ }^{1}$, Anson Kunjumon George ${ }^{1}$, \\ Vandana Kalwaje Eshwara', S.S. Prasad ${ }^{1}$ and Kiran Chawla ${ }^{2}$ \\ ${ }^{1}$ Department of Microbiology, Kasturba Medical College, Manipal, Manipal University, India \\ ${ }^{2}$ Department of Surgery, Kasturba Medical College, Manipal, Manipal, India \\ *Corresponding author
}

\section{Keywords \\ Cystic \\ Echinococcosis, \\ Echinococcus \\ granulosus, \\ Hydatid disease, \\ Seropositivity, \\ Parasitic zoonoses.}

\section{Article Info}

Accepted:

12 November 2016

Available Online:

10 December 2016

\section{A B S T R A C T}

Hydatid disease is an important emerging neglected disease worldwide, with significant geographic variation in seroprevalance. The disease is commonly diagnosed on basis of clinical suspicion, imaging and serology. This study was conducted to evaluate our experience with serology in diagnosing hydatid disease in terms of identifying the numbers of patients testing positive for antibodies against Echinococcus, and to study their clinical profile. This retrospective study included all patients who tested for anti-Echinococcus IgG antibodies by ELISA in the years 2014-2015. The clinical characteristics of seropositive patients were contrasted with seronegative patients, and the test results were correlated with radiological findings and, where performed, with histopathological studies. Analysis was performed on SPSS (IBM, Inc). Chi-square test was used to statistically compare between patient groups. Out of 54 patients evaluated by serology for Echinococcosis during the study period, Fourteen (26\%) were seropositive. The two groups were comparable with respect to age, gender and most hematological parameters, excepting eosinophilia, which was more frequent among seropositive patients ( $28.6 \%$ vs. $2.5 \%$; $=0.01)$. Alkaline phosphatase also tended to be higher among seropositives $(42.9 \%$ vs $20 \%$; $\mathrm{p}=0.09)$. Liver was the most frequent site involved (12 patients; $86 \%$ ). Of the 29 patients who also underwent biopsy, all the seven patients with positive biopsy were seropositive, suggesting $100 \%$ sensitivity. The specificity was $81.8 \%$, but this might be a lower estimate due to potentially high rate of false-negative biopsies, as all the seropositive patients also had imaging features suggestive of disease. The positive and negative predictive values were $63.6 \%$ and $100 \%$, respectively. ELISA for detection of anti-Echinococcus antibodies is a simple serological test that helps in correlation with imaging finding in the diagnosis and subsequent management of hydatid disease.

\section{Introduction}

Hydatid disease, caused by larval stage of Echinococcus granulosus is a commonly seen parasitic zoonosis in Mediterranean countries, Eastern Europe, North and East Africa, Central Asia, Australia and South America (Grosso et al., 2012). In India, the 
disease is more prevalent in Andhra Pradesh, Tamil Nadu and Kashmir. The disease has been included in the list of neglected tropical disease by World Health Organization (WHO) for its strategic plans for the control of listed diseases. Humans, being the accidental dead end intermediate hosts, manifest the disease as slow growing cystic lesion in affected organ. Though physical imaging techniques give definitive evidence of disease, serology does play a main role in diagnosis and monitoring of illness (Kayal et al., 2014). A positive serology for hydatid disease helps in identifying the disease burden in the region as it remains positive even after surgery and treatment (Sarkari et al., 2015).

The objective of this study was to look into the anti-Echinococcus IgG antibody seropositivity rates in the background of clinical epidemiology of suspected cases of hydatid disease.

\section{Materials and Methods}

This study was a retrospective analysis of suspected cases of hydatid disease who were tested for presence of $\operatorname{IgG}$ antibodies for Echinococcus granulosus by ELISA in years 2014 and 2015. The cases were traced from laboratory records. The assay used on all samples was an indirect Enzyme Linked Immunosorbent Assay (ELISA) by NOVALISA test kits (NovaTecImmun diagnostic, $\mathrm{GmbH}$ ) as per the manufacturer's guidelines. The test results were calculated using NovaTec-Units (NTU). NTU was calculated by the formula (Absorbance value of test / Cut-off) x 10. As per the manufacturer's guidelines, NTU $<9$ was interpreted as negative, 9-11 NTU as borderline/grey zone, and NTU >11 as positive. Clinical details were collected for all the cases. Laboratory parameters were compared between seropositive and seronegative patient groups, using chisquare test for evaluating statistical significance, on Statistical Package for Social sciences version 15 (IBM, Inc). Statistical significance was considered when $\mathrm{p}$ value of $<0.05$ was obtained. Sensitivity and specificity of ELISA was calculated using histopathology as standard for those cases where histopathology results were available.

\section{Results and Discussion}

A total of 54 patients were suspected of clinically and/or radiologically suffering from hydatid disease during the study period, and tested for IgG antibodies against hydatid disease. The mean age of all the patients was 43.9 years (range: 10-98 years). Highest numbers of cases were seen among age group of 40-49 years. Males and females constituted a nearly identical number of patients with suspected hydatid disease (26 and 28, respectively). However, male patients were relatively younger compared to females, with a mean age of 37.5 and 49.9 years, respectively. Frequency distribution of age and gender is shown in figure I.

Fourteen patients tested seropositive for antibodies against hydatid disease, resulting in a $26 \%$ seropositivity rate. Liver was the most common organ involved among seropositive patients, with 12 out of 14 (86\%) having evidence of liver involvement. Moreover, all the 12 patients with hepatic disease had symptom of upper abdominal pain secondary to liver involvement. Out of the 12 cases with liver hydatid cysts, 8 (66 $\%)$ had right lobe involvement and $3(25 \%)$ had left lobe involvement; bilateral lobar involvement was seen in one case. Gall bladder involvement was seen in only one case. When a comparison was made between the seropositive and seronegative cases with respect to various demographic 
and clinical variables, there was no significant difference observed in age, gender distribution and most other laboratory parameters between the two groups. The only exception was a significantly higher frequency of eosinophilia in the seropositive group when compared to patients who had tested negative; four patients out of $14(28.6 \%)$ that tested positive had eosinophilia against only one $(2.5 \%)$ among the 40 seronegative patients (Table 1).

A total of 29 patients underwent histopathological evaluation for confirmation of diagnosis, 11 of whom were seropositive. All the 7 patients who were confirmed to have histopathological evidence of disease tested seropositive, leading to a sensitivity of $100 \%$. However, of the remaining 22 histopathologically negative patients, ELISA reported seronegativity in 18, signifying a $81.8 \%$ specificity. The positive and negative predictive values of serology as against histopathology were $63.6 \%$ and $100 \%$, respectively (Table 2). However, all the 13 seropositive cases who underwent radiological evaluation also had imaging features suggestive of Hydatid disease.

Of the 14 patients, 12 were managed by surgical removal of the cyst as the primary treatment. Two patients received albendazole as primary treatment and were advised surgery at a later date. Both the patients defaulted, and later presented with complications of rupture of cyst and were treated surgically. One of these patients died, and the other was discharged against medical advice. 11 out of the 12 patients who underwent primary surgical therapy showed improvement. One patient died due to post-operative thromboembolism.

This retrospective study was conducted to identify the frequency and clinical characteristics of patients testing positive by serology for hydatid disease. Hydatid disease is considered as an important emerging neglected disease worldwide (Torgerson et al., 2010; Mutwiri et al., 2013). The disease is most frequently diagnosed by imaging studies, but serological tests for identification of specific antibodies are utilized to increase the diagnostic yield and in identification of early disease, as imaging is effective only late stages of infection (Zhang et al., 2012). At our center, serological evaluation for hydatid disease was infrequent, with only 54 samples sent for detection of antibody against the parasite in a period of 2 years. Of these, only 14 tested positive, resulting in a seropositivity rate of $26 \%$. Wide geographic variation in prevalence of the disease has been recognized, ranging from $5.09 \%$ to 89.4\% (Fomda et al., 2015; Park et al., 2015). As the disease has slow progression and remains asymptomatic for a long time, seroprevalence is affected by the population tested. The studies which have evaluated the defined asymptomatic groups like animal breeders or population from one particular geographical area have reported lower prevalence rates (Fomda et al., 2015; Akalin et al., 2014). However the studies done on symptomatic individuals have shown a higher seroprevalence (Fomda et al., 2015). In line with this reasoning, as we evaluated suspected cases of cystic Echinococcosis, the prevalence of disease in the community is likely to be much lower.

There is no established gender or age preponderance for the disease. However, the prevalence of hydatid disease is expected to increase with age, as newer infective foci continue to appear throughout life. This pattern was not observed in our study, with nearly $2 / 3^{\text {rd }}$ of the patients testing seropositive being younger than 40 years. Various studies have reported differing 
demographic data. For instance, in a study reporting seroprevalance among animal breeders in Turkey, a significant correlation was reported between age group of 30-39 years and seropositivity. The same report also had more females who were seropositive than males (Akalin et al., 2014). Though male preponderance was noted among the suspected cases, the seropositive group had equal males and females in our study.

The liver was the most frequent organ involved in our study, with all except 2 seropositive patients having evidence of liver involvement by imaging. The pathogenesis of the disease naturally makes the liver the most commonly affected organ. And in liver it is the right lobe that is more commonly affected due the course of portal circulation (Pakala et al., 2016). Hydatid cyst remains asymptomatic for long time until it enlarges in size to compress the other structures around. The symptoms are mainly due to compression of the enlarging cyst on surrounding structures. As was noted in our study, the most common presentation in case of liver hydatid cyst is abdominal discomfort (Pakala et al., 2016; Siracusano et al., 2009).

In the present practice of medicine, diagnosis of cystic Echinococcosis usually made on imaging studies, most commonly ultrasonography. In our cases, the radiological evidence was mainly obtained by contrast enhanced CT scans and cases were not classified depending on the ultrasonography finding. Ultrasonography is the preferred diagnostic imaging, and also provides information on the stage of disease; the WHO Informal Working Group on Echinococcosis (WHO-IWGE) has defined 5 different classes of hydatid disease based on ultrasonography findings (Brunetti et al., 2010). Moreover, several studies have reported that the ultrasonography is more useful in diagnosing cystic Echinococcosis than CT and MRI (Wuestenberg et al., 2014; Stojkovic et al., 2012). When compared with CT scan, MRI has been shown to reproduce the findings of ultrasonography better (Stojkovic et al., 2012).

Immunological investigations are always considered complimentary to imaging in diagnosing Echinococcosis due to lack of sensitivity and specificity. Antibody response in case with Echinococcosis infection largely depends on various factors such as the stage of disease, site of involvement, etc. Therefore false negative results are seen in cases of small cysts, calcified cysts, extrahepatic cysts and cysts in privileged sites (Manzano-Román et al., 2015; Florea et al., 2011). Immunodiagnostic tests are also used for treatment monitoring in addition to primary diagnosis. IgG4 subset estimation is a good marker for treatment outcome; the levels decrease immediately after surgery and remain high in case of recurrent disease (Zhang et al., 2003). Hydatid cyst fluid (HCF), extracts from protoscolises, larval forms and adult worms are potential antigenic sources for the serological diagnosis of hydatid disease. Antigen B and antigen 5 are the most common constituents of HCF which are used for development of immunological tests. Among these, antigen $\mathrm{B}$ is a better antigen as compared to antigen 5 with respect to cross reactivity (Sarkari et al., 2015). Detection of specific IgG subclasses have also shown to have diagnostic significance. Specific IgG4 isotype is shown to be associated with active disease and has been shown as a good prognostic marker in many studies (Sarkari et al., 2015; Manzano-Román et al., 2015). In our study, we used commercial ELISA kit to detect total IgG levels using purified Echinococcus multilocularis antigen. The test result was expressed in terms of NTU. A 
value below 9 is considered negative. In our study we did not find any discordant result with the test method. But a $15 \%$ rate false positive and false negative result was reported by Florea et al., (2011) for the same kit. It was also opined in the article that the NTU has to be interpreted in the background of individual clinical background.

Table.1 Comparison of laboratory parameters among patients with suspected Hydatid disease

\begin{tabular}{|c|c|c|c|c|}
\hline \multicolumn{2}{|l|}{ Variables } & $\begin{array}{l}\text { Seropositive group } \\
(\mathrm{n}=14)\end{array}$ & $\begin{array}{l}\text { Seronegative } \\
\text { group }(n=40)\end{array}$ & p value \\
\hline \multirow[t]{4}{*}{ Age } & $<18$ years & $3(21.4 \%)$ & $1(2.5 \%)$ & \multirow[t]{4}{*}{0.12} \\
\hline & 19-39 years & $6(42.9 \%)$ & $11(27.5 \%)$ & \\
\hline & $40-59$ years & $3(21.4 \%)$ & $17(42.5 \%)$ & \\
\hline & $>60$ years & $2(14.3 \%)$ & $11(27.5 \%)$ & \\
\hline \multirow[t]{2}{*}{ Gender } & Males & $7(50 \%)$ & $19(47.5 \%)$ & \multirow[t]{2}{*}{0.87} \\
\hline & Females & $7(50 \%)$ & $21(52.5 \%)$ & \\
\hline \multirow{3}{*}{$\begin{array}{l}\text { Total WBC } \\
\text { count }\end{array}$} & Low & $1(7.1 \%)$ & $1(2.5 \%)$ & \multirow[t]{3}{*}{0.64} \\
\hline & normal & $8(57.1 \%)$ & $27(67.5 \%)$ & \\
\hline & high & $5(35.7 \%)$ & $12(30.0 \%)$ & \\
\hline \multirow{3}{*}{$\begin{array}{l}\text { Absolute } \\
\text { Neutrophil } \\
\text { count }\end{array}$} & Low & $2(14.3 \%)$ & $4(10.0 \%)$ & \multirow[t]{3}{*}{0.68} \\
\hline & Normal & $10(71.4 \%)$ & $26(65.0 \%)$ & \\
\hline & High & $2(14.3 \%)$ & $10(25.0 \%)$ & \\
\hline \multirow{3}{*}{$\begin{array}{l}\text { Absolute } \\
\text { lymphocytes }\end{array}$} & Low & $7(50.0 \%)$ & $20(50 \%)$ & \multirow[t]{3}{*}{0.63} \\
\hline & Normal & $7(50.0 \%)$ & $18(45 \%)$ & \\
\hline & high & $0(0 \%)$ & $2(5 \%)$ & \\
\hline \multirow{3}{*}{$\begin{array}{l}\text { Absolute } \\
\text { eosinophils }\end{array}$} & Low & $4(28.6 \%)$ & $14(35.0 \%)$ & \multirow[t]{3}{*}{0.01} \\
\hline & Normal & $6(42.9 \%)$ & $25(62.5 \%)$ & \\
\hline & high & $4(28.6 \%)$ & $1(2.5 \%)$ & \\
\hline \multirow[t]{2}{*}{ Total Bilirubin } & Normal & $12(85.7 \%)$ & $33(82.5 \%)$ & \multirow[t]{2}{*}{0.78} \\
\hline & High & $2(14.3 \%)$ & $7(17.5 \%)$ & \\
\hline \multirow[t]{2}{*}{ AST } & Normal & $10(71.4 \%)$ & $28(70.0 \%)$ & \multirow[t]{2}{*}{0.92} \\
\hline & High & $4(28.6 \%)$ & $12(30.0 \%)$ & \\
\hline \multirow[t]{2}{*}{ ALT } & Normal & $13(92.9 \%)$ & $30(75.0 \%)$ & \multirow[t]{2}{*}{0.15} \\
\hline & High & $1(7.1 \%)$ & $10(25.0 \%)$ & \\
\hline \multirow[t]{2}{*}{ ALP } & Normal & $8(57.1 \%)$ & $32(80.0 \%)$ & \multirow[t]{2}{*}{0.09} \\
\hline & High & $6(42.9 \%)$ & $8(20.0 \%)$ & \\
\hline \multirow[t]{2}{*}{ Urea } & Normal & $12(85.7 \%)$ & $34(85.0 \%)$ & \multirow[t]{2}{*}{0.94} \\
\hline & High & $2(14.3 \%)$ & $6(15.0 \%)$ & \\
\hline \multirow[t]{2}{*}{ Creatinine } & Normal & $14(100.0 \%)$ & $35(87.5 \%)$ & \multirow[t]{2}{*}{0.16} \\
\hline & High & $0(0 \%)$ & $5(12.5 \%)$ & \\
\hline
\end{tabular}


Table.2 Comparison of serology results with results of Histopathological evaluation

\begin{tabular}{|l|l|l|l|l|}
\hline \multirow{2}{*}{ Serology } & \multicolumn{2}{|l|}{ Histopathological evidence } & Total \\
\cline { 2 - 5 } & $\begin{array}{l}\text { Positive } \\
\text { (Number of } \\
\text { case) }\end{array}$ & $\begin{array}{l}\text { Negative } \\
\text { (Number of } \\
\text { case) }\end{array}$ & $\begin{array}{l}\text { Not done } \\
\text { (Number of } \\
\text { case) }\end{array}$ & 3 \\
\hline $\begin{array}{l}\text { Positive } \\
\text { (Number of cases ) }\end{array}$ & 7 & 4 & 3 & 14 \\
\hline $\begin{array}{l}\text { Negative } \\
\text { (Number of cases })\end{array}$ & 0 & 18 & 22 & 40 \\
\hline Total & 7 & 22 & 25 & 54 \\
\hline
\end{tabular}

Fig.1 Gender distribution across age groups among patients with suspected Echinococcosis

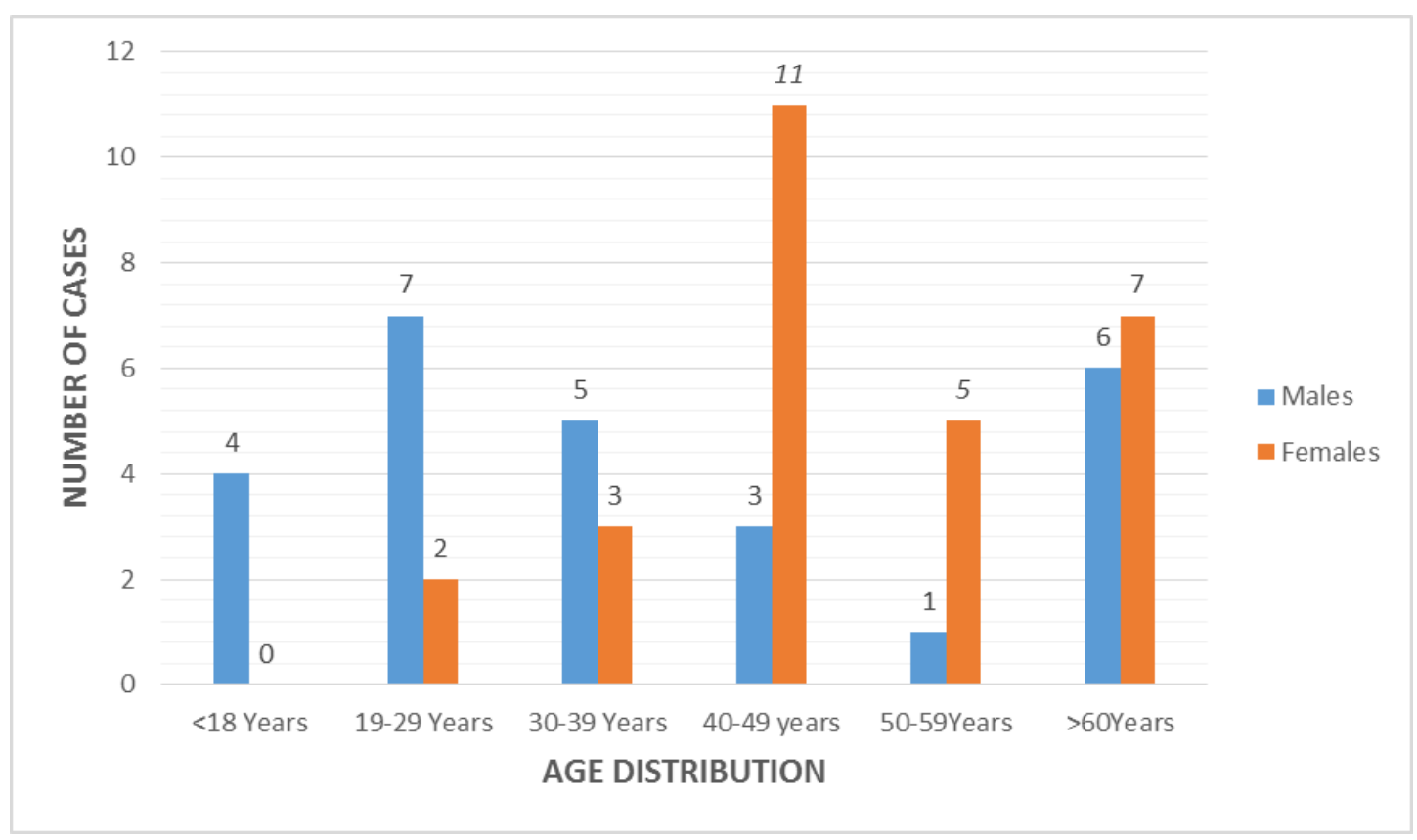

Histopathological examination of a suspected hydatid cyst is confirmatory, but is not routinely performed, as imaging and serological tests are usually diagnostic, and it has been considered that biopsy harbors the risk of anaphylaxis, and dissemination of disease. However, it may be of benefit in confirming diagnosis when other tests are ambiguous, or in cases with presentation at unusual sites (Dissanayake et al., 2016; Das et al., 2014). More than half of the patients in our study underwent histopathological evaluation, of which only 7 were reported positive. In comparison with histopathology, serology had $100 \%$ sensitivity, but a lower measured specificity of $81 \%$. However, it must be noted that all the 13 seropositive patients had evidence of hydatid cyst on imaging, suggesting a possibly increased false negative rate on histopatholgical evaluation due to unexplained reasons. Serological test-specificities have been known to be affected by anti-P1 antibodies, in addition to other factors such as other helminth infections, and location/size of cyst, stage of disease, etc (Brunetti et al., 2011). 
Comparison of laboratory data between seropositive and seronegative patients showed no significant difference between two groups, except for higher frequency of eosinophilia among seropositive. In general, elevated liver enzymes are seen in only in $40 \%$ of liver hydatid cases, and it is usually ALP which is increased (Pakala et al., 2016). In the present study, there has been a similar trend towards elevated ALP in seropositive group.

Management proposed by WHO is dependent on the WHO-IWGE grade of the lesion. Main treatment modalities mentioned are albendazole and PAIR [puncture, aspiration, injection, respiration] Medical therapy alone using albendazole is indicated only in small unilocular cysts with a size < $5 \mathrm{~cm}$. Percutaneous treatment along with adjunctive therapy is used in settings where albendazole treatment is not feasible (Brunetti et al., 2010; Nabarro et al., 2015).

Surgery is the choice of treatment modality in case of complicated cases and in large cysts with a size of $>10 \mathrm{~cm}$. Complications mainly include raptured cyst, cysts with biliary fistulae, cysts compressing vital structures, cysts with secondary infection or hemorrhage (Brunetti et al., 2010). In our study $71.4 \%$ patients underwent definitive surgical therapy. Complication following medical therapy was $14 \%$. All patients who underwent surgery recovered.

In conclusion, serology for detection of antibodies against hydatid disease is infrequently utilized. However, it is a simple test to confirm the diagnosis, and proved to be robust in our experience, with $100 \%$ sensitivity when compared with imaging and/or histopathology. The calculated specificity of $81.8 \%$ when compared to biopsy is likely an underestimation, as serology results correlated with imaging findings in all of the seropositive patients.

\section{References}

Akalin, S., Kutlu, S.S., Caylak, S.D., Onal, O., Kaya, S., Bozkurt, A.I. 2014. Seroprevalence of human cystic echinococcosis and risk factors in animal breeders in rural communities in Denizli, Turkey. J. Infect. Dev. Ctries., 8(9): 1188-94.

Brunetti, E., Garcia, H.H., Junghanss, T. 2009. International CE Workshop in Lima, Peru, 2009. Cystic echinococcosis: chronic, complex, and still neglected. PloS. Negl. Trop. Dis., 5: e1146.

Brunetti, E., Kern, P., Vuitton, D.A. 2010. Writing Panel for the WHO-IWGE. Expert consensus for the diagnosis and treatment of cystic and alveolar echinococcosis in humans. Acta Trop., 114(1): 1-16.

Das, D.K., El-Sharawy, M., Ayyash, E.H., AlEnezi, N.A., Iqbal, J.R., Madda, J.P. 2014. Primary hydatid cyst of the supraspinatus muscle: complete removal of the germinal layer and cytodiagnosis by fine-needle aspiration. Diagn. Cytopathol., 42: 268-72.

Dissanayake, P.I., Chennuri, R., Tarjan, G. 2016. Fine-needle aspiration diagnosis of primary hydatid disease of the thyroid; first reported case in the USA. Diagn. Cytopathol., 44: 334-7.

Florea, A., Vlad, L., Cozma, V., Coroiu, Z. 2009. Serological diagnosis of cystic echinococcosis by the ELISA technique, in the cases hospitalized in the surgical clinic no. III and internal medicine no. III of Cluj-Napoca, during October 2006 - December 2009. Sci. Parasitol., 12(3): 167-71.

Fomda, B.A., Khan, A., Thokar, M.A., Malik, A.A., Fazili, A., Dar, R.A. et al. 2015. Sero-epidemiological survey of human cystic echinococcosis in Kashmir, North India. PLoS One, 10(4): e0124813. 
Grosso, G., Gruttadauria, S., Biondi, A., Marventano, S., Mistretta, A. 2012. Worldwide epidemiology of liver hydatidosis including the Mediterranean area. World J. Gastroenterol., 18(13): 1425-37.

Kayal, A., Hussain, A. 2014. A comprehensive prospective clinical study of hydatid disease. ISRN Gastroenterol., 514757. Available from: doi:10.1155/2014/514757 [Accessed 28th September 2016].

Manzano-Román, R., Sánchez-Ovejero, C., Hernández-González, A., Casulli, A., Siles-Lucas, M. 2015. Serological diagnosis and follow up of human cystic echinococcosis: a new hope for the future? Biomed. Res. Int., 428205.

Mutwiri, T., Magambo, J., Zeyhle, E., Mkoji, G.M., Wamae, C.N., Mulinge, E. 2013. Molecular characterisation of Echinococcus granulosus species/strains in human infections from Turkana, Kenya. East African Med. J., 90(7): 235-40.

Nabarro, L.E., Amin, Z., Chiodini, P.L. 2015. Current management of cystic echinococcosis: a survey of specialist practice. Clin. Infect. Dis., 60(5): 721-8.

Pakala, T., Molina, M., Wu, G.Y. 2016. Hepatic Echinococcal Cysts: A Review. J Clin. Transl. Hepatol., 4(1): 39-46.

Park, S.J., Han, S.S., Anvarov, K., Khajibaev, A., Choi, M.H,. Hong, S.T. 2015. Prevalence of serum IgG antibodies to cystic echinococcus antigen among patients in an Uzbekistan emergency hospital. Korean J. Parasitol., 53(6): 699-703.

Sarkari, B., Rezaei, Z. 2015. Immunodiagnosis of human hydatid disease: where do we stand? World J. Methodol., 5(4): 185-95.

Siracusano, A., Teggi, A., Ortona, E. 2009. Human cystic echinococcosis: old problems and new perspectives. Interdiscip. Perspect Infect. Dis., 474368.

Stojkovic, M., Rosenberger, K., Kauczor, H.U., Junghanss, T., Hosch, W. 2012. Diagnosing and staging of cystic echinococcosis: how do CT and MRI perform in comparison to ultrasound? PloS Negl. Trop. Dis., 6(10): e1880.

Torgerson, P.R., Keller, K., Magnotta, M., Ragland, N. 2010. The global burden of alveolar echinococcosis. PloS Negl. Trop. Dis., 4: e722.

Wuestenberg, J., Gruener, B., Oeztuerk, S., Mason, R.A., Haenle, M.M., Graeter, T. et al. 2014. Diagnostics in cystic echinococcosis: serology versus ultrasonography. Turk. J. Gastroenterol., 25(4): 398-404.

Zhang, W., Li, J., McManus, D.P. 2003. Concepts in immunology and diagnosis of hydatid disease. Clin. Microbiol. Rev., 16(1): 18-36.

Zhang, W., Wen, H., Li, J., Lin, R., McManus, D.P. 2012. Immunology and immunodiagnosis of cystic echinococcosis: an update. Clin. Dev. Immunol., 101895. Available from: doi:10.1155/2012/101895.

\section{How to cite this article:}

Mridula Madiyal, Barnini Banerjee, Anson Kunjumon George, Vandana Kalwaje Eshwara, S.S. Prasad and Kiran Chawla. 2016. Role of Serology in Diagnosis of Human Hydatidosis: Experience from a Tertiary Care Hospital. Int.J.Curr.Microbiol.App.Sci. 5(12): 195-202. doi: http://dx.doi.org/10.20546/ijcmas.2016.512.021 